\title{
EL 'LOEAR \\ DEL OMRO'
}

\section{EN LA}

(5)

CONSTIRDECIÓN

DL ROL

docente $A$

PARTIR DE LA

CONSTRUECIÓN

DeL ROLDE

DIRECTOR

Carolina Merchán Price

Narda Rosas Martínez
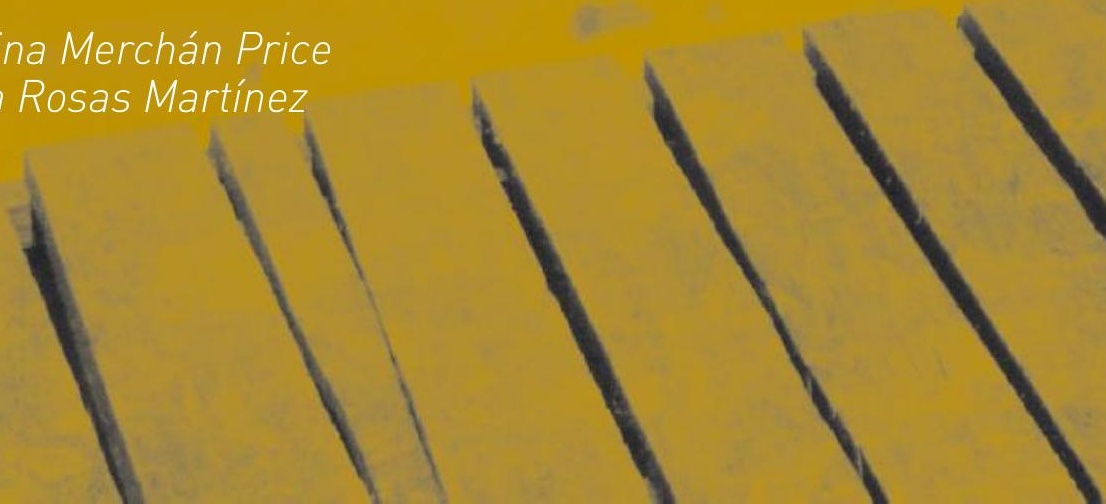


\section{Resumen}

Buscando dar coherencia al proyecto curricular, se inician proyectos de investigación al interior del aula (Énfasis de teatro dramáticol para comprender las transposiciones de saberes específicos que allí se construyen viabilizándolos hacia el espacio escénico pedagógico ${ }^{40}$, sus didácticas y necesidades. Partíamos de la analogía general que se evidencia entre el rol de director y el rol docente en artes escénicas. A través del análisis de los instrumentos fueron apareciendo una serie de pistas para reconsiderar el modelo 'imaginario' que creímos tener para comprender el modelo que desde este proyecto se fue instalando. Desde el punto de vista de la acción de la profesora universitaria, notamos que su función docente consiste en dar ciertos aportes teóricos bajo forma de lecturas (no es ella quien "da la teoría") y sobre todo, otorgar el espacio y el tiempo para que los estudiantes construyan las reflexiones pertinentes que surgen de las articulaciones de los sistemas en los estudiantes.

\section{Palabras clave:}

Rol docente, acción conjunta, rol de director vs. rol docente, espacio escénico pedagógico.

40 Espacio escénico pedagógico corresponde al espacio sugerido donde se desarrollen los procesos propios del teatro como disciplina de formación de sujetos en la escuela. Un espacio escénico privado, extensible e infinito tiene una función específica en la escuela: formar en el conocimiento y en la convivencia; hacer teatro escolar es dotar a los alumnos de un espacio privilegiado para la construcción de su identidad, para el desarrollo de sus capacidades como personas determinados en aprendizajes específicos: corporales, expresivos, interactivos.
The "other's place" within the teacher's role construction from the director's role construction

\section{Abstract}

Since we look for giving consistency to a curriculum project we have begun some research projects inside the classroom (emphasis on drama works) in order to understand the inclusion of specific knowledge built into the educational performance scenery, including their teaching proposals and needs. We started from a visible, overall analogy between the director's role and the teacher's role in performing arts. By an instrument analysis a series of hints has begun to appear in order to rethink the 'imaginary' model we have got to understand the model set up from this project. From the college professor's action perspective, we observe his/her teaching is to offer some theoretical contributions by some readings lit is not him/her who "teaches theory"), but chiefly providing time and scope to students to build their relevant considerations arising from their system connections.

\section{KEYWORDS:}

Teaching role, joint action, director's role versus teacher's role, educational performance scenery.

\section{O "lugar do outro" na construção do rol docente a partir da construção do rol de diretor}

\section{Resumo}

Procurando dar coerência a o projeto curricular, se iniciam projetos de pesquisa no interior da aula lênfase de teatro dramáticol pra compreender as transposições de saberes específicos que ali se constroem viabilizando eles para um espaço cênico pedagógico, suas didáticas e necessidades. Começamos da analogia geral que se visibiliza entre o rol de diretor e rol docente em artes cênicas. Por dentro do analise de instrumentos foram surgindo uma serie de dicas, pra reconsiderar o modelo "imaginário", que achamos ter para compreender o modelo que desde este projeto foi - se instalando desde o ponto de vista da ação da professora universitária, percebemos que sua função docente, significa brindar elementos teóricos, baixo a forma de leituras (não ê ela, quem "da a teoria").e sobre tudo, criar o espaço e o tempo, pra que os estudantes construam as reflexões pertinentes que surgem das articulações dos sistemas nos estudantes.

\section{Palavras chave:}

Rol docente, ação conjunta, rol de diretor vs. rol docente, espaço cênico - pedagógico.

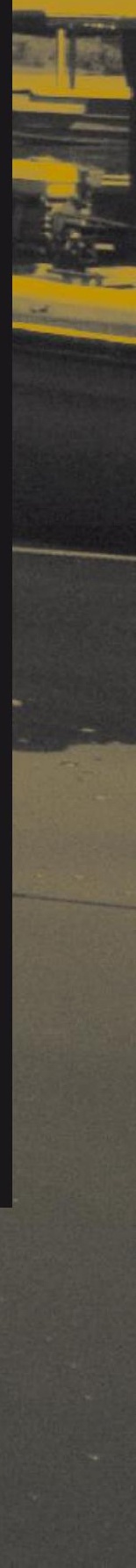




\section{Introducción}

El espacio énfasis de teatro dramático dentro del programa de Licenciatura en Artes Escénicas de la Universidad Pedagógica Nacional corresponde a la puerta de entrada del ciclo de profundización a partir del séptimo semestre de la carrera. Este espacio tiene una duración de tres semestres y una carga horaria de 12 horas en séptimo y octavo semestre y de nueve horas en noveno. Paralelamente los estudiantes inician en octavo semestre la observación de clases en escuelas y espacios de formación con el fin de construir su proyecto de práctica pedagógica, que efectuarán en noveno y décimo semestre. En aras de dar coherencia al proyecto curricular, se inician proyectos de investigación al interior del aula universitaria para comprender las transposiciones de saberes específicos que allí se construyen, viabilizándolos hacia el espacio escénico pedagógico, sus didácticas y necesidades. Durante los primeros años de construcción de los énfasis, esta área se desarrolló en espacios eminentemente dirigidos al aprendizaje de técnicas específicas en cada una de las opciones que presentaba el programa: Teatro dramático, Teatro gestual, Teatro de objetos. Hoy los intereses son otros. Se han definido derroteros más claros hacia la comprensión del sentido de la formación de docentes en artes escénicas para la escuela básica y media. Es en este marco que iniciamos esta investigación en aula en el espacio de Énfasis en Teatro Dramático con el fin de describir y analizar los procesos de formación del rol docente a partir de la construcción del rol de director en este espacio académico.

Al iniciar esta investigación partíamos de la analogía general que se visibilizaba entre el rol de direc- tor y el rol docente en artes escénicas. Esta analogía suponía que algunas de las formas y saberes del director en la gestión de montaje podían ser relacionados con las formas y saberes del futuro rol docente de los estudiantes en el aula escolar. Pensábamos que, en el juego de roles que implicaba nuestro dispositivo, se evidenciarían algunas de esas formas, la manera de interrogar las posibles transformaciones de las prácticas artísticas que, desde una futura acción docente, se ampliarían en las formas de convocar a los alumnos para llevar a cabo un programa exitoso en la escuela.

La problemática partía del hecho de que no estábamos teniendo en cuenta que quienes hacen parte del énfasis son estudiantes en formación de licenciatura y no de actuación profesional, y que en el aula están justamente formando su rol de director en un contexto de formación de formadores. Por tanto, al avanzar en el análisis desde el dispositivo socioprofesional directoràactoràmontaje como dispositivo de aprendizaje de saberes disciplinares, fueron emergiendo elementos que amplían los lugares de formación y dan pistas de cohesión al interior del mismo espacio en tanto formación de rol de director, formación de rol docente y construcción de saberes didácticos para el teatro escolar. Es decir, partimos de cuestionar y problematizar la hipótesis de la transferencia de la equivalencia rol director $=$ rol docente, para darnos cuenta de que la dimensión formativa del dispositivo va más allá de la construcción y transferencia entre los roles. Como lo mostrarán nuestros análisis, es también el juego complejo de alternancias y desplazamientos y articulación de los roles ejercidos por un mismo individuo (el estudiante) lo que conlleva efectos formativos para la construcción del perfil profesional del futuro docente en artes escénicas.

El objeto de estudio al interior del aula del énfasis es de por sí complejo: las relaciones directoractor, formador-estudiantes, estudiantes, que se construyen a la vez para formadores como para directores en la asunción de comportamientos y saberes propios de los dos campos disciplinares (pedagogía y artes escénicas). Diferenciamos que, para ser docentes en artes escénicas, los estudiantes deben construir su mirada desde la experticia disciplinar que ofrece la dirección escénica pero, además, dominar igualmente las dimensiones distintas que supone el saber en/de los ejercicios escénicos como medio formativo para estudiantes y alumnos ${ }^{41}$.

Marco teórico: de los saberes emblema del director en las acciones de re-personalización y re-contextualización en el espacio institucional

Los espacios de construcción del rol de director, y aún del rol del actor, están situados en las situaciones de representación propias del entrenamiento escénico. Estas situaciones crean ambientes de representación (Barba, 1998), que se proponen desde la formación de formadores en artes escénicas como ambientes de aprendizaje a través de los cuales se generan infinitud de espacios posibles de desarrollo, de comprensiones y expresión. En éstas, se exige de quienes participan, disposiciones particulares que implican a su vez conciencia de su actuar diferen-

\footnotetext{
41 Para una lectura más clara en el marco de este texto, llamamos "estudiantes" a los futuros docentes al interior de la Universidad, y "alumnos" a los niños y niñas que hacen parte de la escuela Básica y Media.
} 
ciando las maneras cotidianas de las extra-cotidianas. En términos disciplinares, estas disposiciones implican al cuerpo y a la persona en la construcción de comportamientos específicos propios de la actuación (Barba, 1998). En el plano de esta investigación se centra la mirada de la comprensión en la construcción del rol del director en el espacio académico énfasis de teatro dramático, sus gestos y sus funciones.

\section{El director como vector} de transmisión y/o transformación de las prácticas teatrales

En las manos del director recaen tareas como la interpretación y análisis de la obra escrita (texto dramáticol con el fin de comprender la totalidad del texto y los sucesos de las acciones escénicas. Para ello requiere entender en profundidad las estructuras que forman las obras de teatro, además de los contextos sociales en las que fueron escritas, en los que sucede la acción ficticia (Stanislavsky, 1961) y en los que será actualizada por un montaje específico. Sumado a esto, se le reconoce una dimensión creativa por cuanto esta actualización se adapta a una época -y por ello a un nuevo contexto social-, en la que las necesidades de comunicación son unas y particulares, y otros medios y formas expresivas se movilizan y cambian (Cantillo, 2000). Finalmente, destacaremos que este trabajo de dirección no se hace en solitario, y que por lo tanto el director debe igualmente desarrollar competencias relativas al trabajo de construcción conjunta con el grupo de trabajo en cuestión.

En las prácticas socioprofesionales el director se hace a partir de búsquedas creativas que le permiten desarrollar su universo estético. Paralelamente los actores con quienes trabaja se forman en esa escuela que poco a poco se va reconociendo como un universo propio de su autoría. En esta medida los actores son quienes 'hacen escuela' en tanto trabajan con este o aquel otro director. En ocasiones, un actor tiene algo 'más que decir', o 'debe buscar otros rumbos' y suscribe su propio grupo convocando actores.

Esta manera de formar actores ha encontrado, sin embargo, nuevos contextos de desarrollo. Algunas universidades han abierto programas de arte dramático y es en el aula universitaria en donde se forman los actores con directores contratados para su formación. También funcionó así en un principio al interior de la Universidad Pedagógica. Sin embargo, al llegar a la consolidación del ciclo de profundización de la Licenciatura en Artes Escénicas, se pensó en la importancia de crear el énfasis de teatro dramático como el espacio para formar directores en la conciencia de estar formándose como tales. Se daba entonces por hecho que al formarse como directores se estaban formando también como docentes, sin entrar a puntualizar cómo se daban esas transferencias, en qué dimensiones se aportaba a uno u

ESQUEMA 1. ESPACIO ÉNFASIS DE TEATRO DRAMÁTICO COMO IMBRICACIÓN DE DOS SISTEMAS DIDÁCTICOS

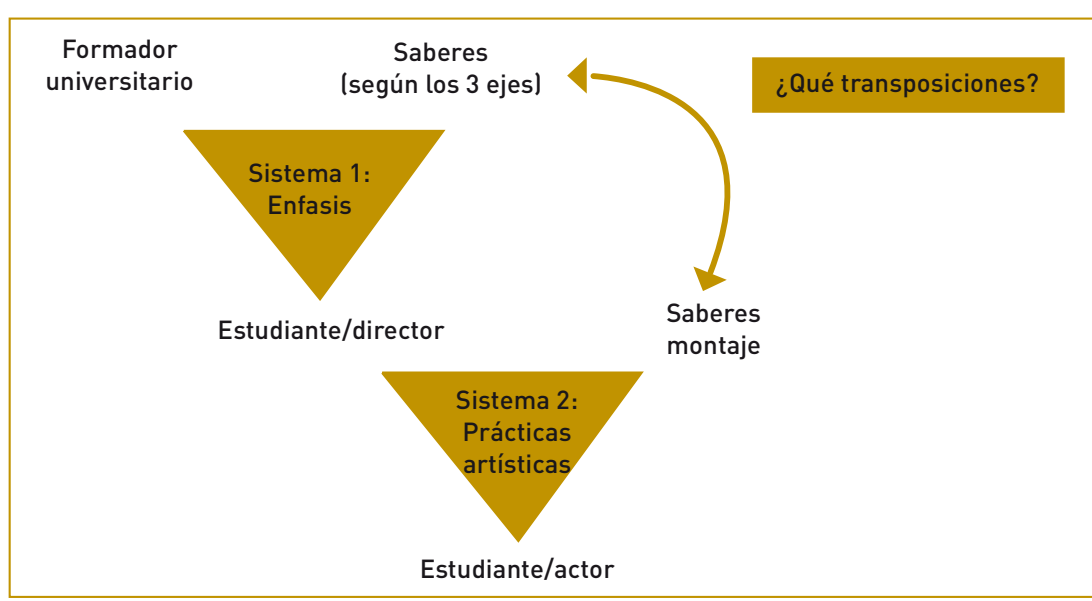

otro rol, cuáles eran las diferenciaciones necesarias.

El dispositivo del énfasis de teatro dramático: espacios complejos de interacciones formadoras

En el espacio énfasis de teatro dramático, el modelo que se desarrolla para la construcción del rol de director al interior de la licenciatura está a cargo de un formador universitario, consciente de la importancia de construir en cada uno de los estudiantes su propia identidad como directores a la vez que de docentes Isistema 1). Propone los contenidos y objetivos de la clase énfasis de teatro dramático que se van complejizando a medida en que avanzan los semestres, para terminar en noveno semestre con una práctica de dirección que aquí llamaremos práctica artística (sistema2).

\section{El esquema general} del espacio énfasis de teatro dramático y su problematización

En el dispositivo de formación, la estructura de la clase se transforma desde séptimo hasta noveno semestre en varios aspectos. Aquí señalaremos uno en particular: en séptimo y octavo semestre, los estudiantes realizan

\section{.}

(n)




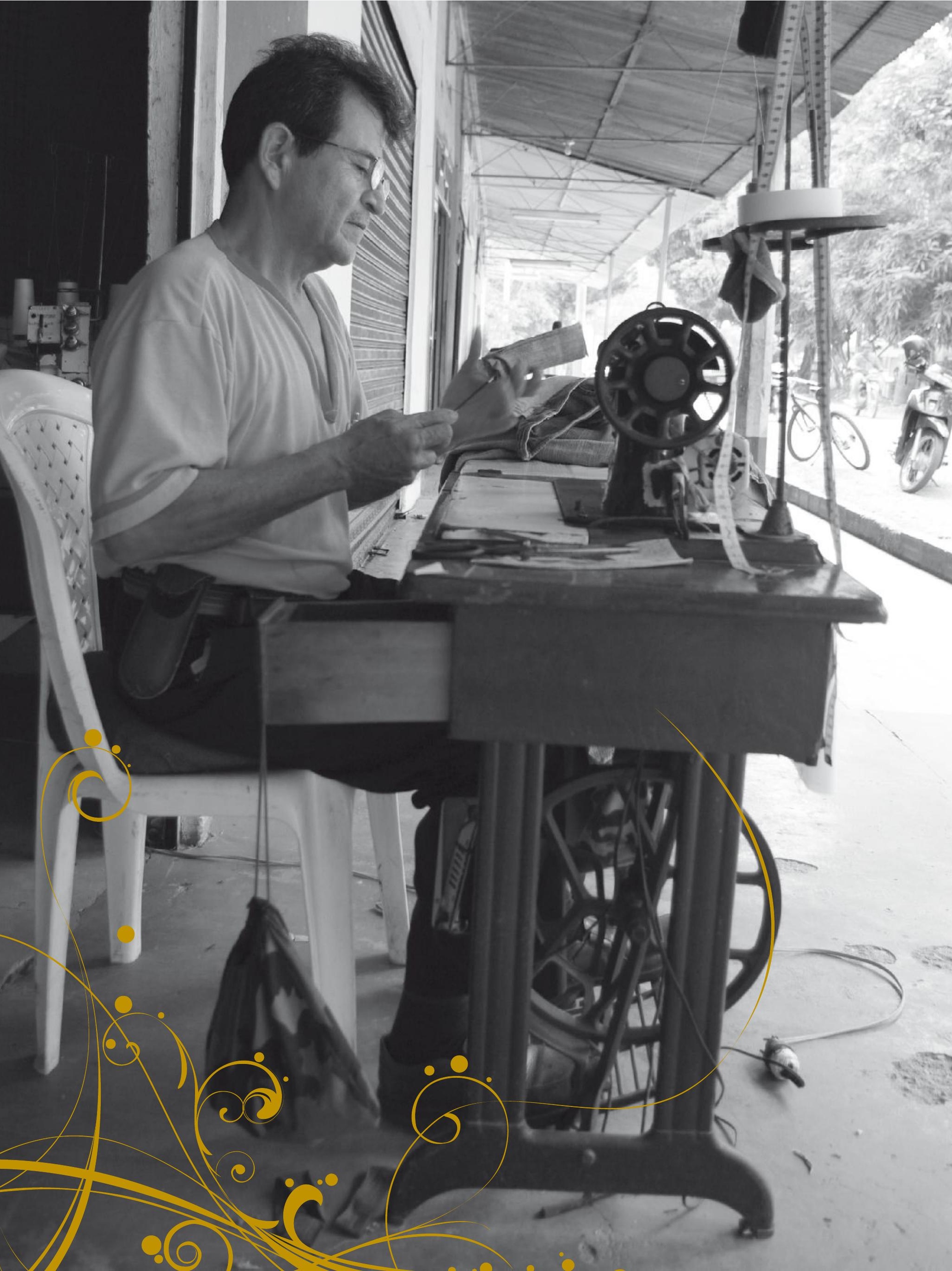


las tareas propias del programa con sus compañeros de clase, en la asunción de los roles de director, de público, de actores, de críticos. En noveno semestre, los estudiantes del énfasis deben realizar el ejercicio de dirección: la práctica artística, contando como actores con estudiantes de los primeros semestres de la formación. Es entonces cuando el espacio formal del énfasis de teatro dramático se amplía en dos espacios, que en el marco de este estudio denominaremos sistema (didáctico) de formación 1 y sistema (didáctico) de prácticas artísticas 2 (ver esquema), subrayando con el término de 'didáctico' que son espacios para la formación de los estudiantes-directores.

Esta práctica artística no supone certificación de ningún tipo para quienes harán el papel de actores; lo que supone unas motivaciones muy particulares de parte de los 'directores', pues deberán sostener la integración del 'grupo' desde el inicio hasta el fin del proyecto, cuya duración gira alrededor de tres meses. La formadora del énfasis no interfiere directamente dentro de los espacios de la práctica artística (sistema 2). Vemos entonces que tenemos un espacio académico, el énfasis de teatro dramático dividido en dos sistemas didácticos que comprometen el desarrollo del programa de aula. Por tanto, son los estudiantes quienes articulan aquellos saberes que hacen parte de los contenidos del programa general y los experiencian en la práctica artística, en un ir y venir constante que les permite alternar entre espacios de reflexión y espacios de acción.

\section{A. Cuáles son las características del sistema didáctico 1 \\ + Es el espacio para la cons- trucción de conocimiento a partir}

de la discusión y el análisis de los autores de referencia: Estructuras dramáticas y su devenir histórico ${ }^{42}$, Puesta en escena y su valor estético ${ }^{43}$ y Observación y escucha ${ }^{44}$.

+ Es el espacio para la socialización y la discusión de los avances y dificultades en el sistema didáctico 2.

+ Está a cargo de un formador universitario.

\section{Cuál es la característica del formador}

+ El formador dirige la clase en tanto regula el cronograma y el programa a seguir. Este cronograma involucra la lectura y análisis de los saberes emblemáticos de la historia de la dirección y el teatro que han marcado hito en el campo.

+ Abre espacios de reflexión alrededor de lo que sucede en las prácticas artísticas, sistema 2.

\section{Cuál es la característica del estudiante en el sistema didáctico 1 \\ + Es un estudiante reflexivo. A} partir de los contenidos del programa de base, cada uno de los estudiantes debe analizar y socializar lecturas puntuales.

+ La actitud reflexiva se extiende a los trabajos de formulación del proyecto y desarrollo de la práctica artística.

+ En un principio el espacio académico suponía la lectura y el análisis de los enunciados de los grandes maestros de la dirección para llevarlos a la práctica al-piede-la-letra, a la manera de repetir saberes enciclopédicos. Hoy vemos que el modelo es mucho más dialéctico.

42 Las poéticas, tanto clásicas como modernas. Aristóteles, Horacio, Lessing, Ribera. 43 Grotowsky, Stanislavsky, Meyerhold, Brook Barba, Brecht, Mukarovsky. 44 Op.cit.

\section{B. Sistema didáctico 2}

(la práctica artística)

Es el espacio para llevar a cabo los ejercicios de dirección escénica.

+ Cuál es el papel del estudiante/director

+ Consecución de espacios de entrenamiento.

+ Propuesta de proyecto de dirección: planes de entrenamiento, cronograma de trabajo, gestión de escenografía, vestuario, luces.

+ Sostén del grupo de trabajo.

\section{Cuál es el papel de los actores}

+ El papel del actor es sustantivo. De su participación y compromiso depende el éxito del dispositivo. Puntualidad, responsabilidad y disposición en la construcción del medio son tres de las actitudes necesarias para el trabajo. Hacerse grupo supone un trabajo permanente de coconstrucción.

+ Señalar críticamente la recepción de informaciones y acotaciones del director y viabilizar la fluidez en la comunicación director/actor.

+ El trabajo fuera del aula correspondiente a la comprensión y memorización de los textos, a la búsqueda propia del actor que es el elemento previo al trabajo conjunto en el aula. Sin este trabajo, la fluidez del grupo se resiente.

\section{Sistema didáctico indirecto 3}

+ Aunque no lo tenemos en el registro del esquema 1 , este sistema está presente en el desarrollo del dispositivo del énfasis de teatro dramático en permanencia. Nos referimos a la proyección de los aprendizajes de los estudiantes a través de su práctica artística hacia la futura práctica pedagógica. Los estudiantes que participaron en la presente investigación tuvieron un semestre de práctica formativa en sexto semestre. Es decir, los referentes 
hacia la docencia comienzan a hacer parte del discurso que deben integrar en las tensiones entre uno y otro rol y orienta in fine las reflexiones y articulaciones posibles entre los dos sistemas didácticos aquí presentados.

\section{Procesos de re-personalización y re-contextualización del saber teatral}

Según la teoría de la transposición didáctica (Chevallard, 1990). los procesos de producción social del saber implican fenómenos de des-contextualización y des-personificación. Para ser transmitidos, los textos del saber necesitan, en efecto, ser separados de las circunstancias históricas y sociales en los que se originaron con el fin de construir así una lógica discursiva interna. Para que durante su transmisión estos saberes no se queden únicamente como elementos emblemáticos y rígidos, los procesos de aprendizaje implican re-contextualizar y re-personalizar esos saberes (Sensevy, Schubauer-Leoni et. al., 2000). Desde el dispositivo estudiado, uno de los objetivos que orientó nuestra investigación fue el de describir estos procesos de re-contextualización: adaptación de las circunstancias dadas de la situación didáctica 2; y de repersonalización de los mismos: construcción y desarrollo de un proyecto de dirección coherente desde su rol de director. Esto en la medida en que los estudiantesdirectores están confrontados en este dispositivo, no solamente a los saberes discursivos sobre el teatro que provienen básicamente de la lectura de textos teóricos, sino que deben igualmente enfrentar la práctica teatral desde sus montajes. Como lo mostrarán nuestros análisis, los procesos de re-contextualización y re-per- sonalización operan en este tipo de dispositivo a partir del 'lugar de tensiones' del estudiante-director: sus relaciones con los textos dramáticos y teóricos (sistema 1), sus relaciones con las prácticas teatrales del montaje del texto dramático, sus relaciones con "el otro", estudiante-actor y grupo.

\section{La acción conjunta como vector de los procesos de formación}

Recordemos que el teatro es una práctica colectiva en sí misma. Tiene que ver con el funcionamiento particular de las situaciones formales de enseñanza-aprendizaje. En nuestro caso, estas situaciones se contextualizan en un espacio de creación conjunta, el espacio del aula en la práctica artística en donde los 'directores' construyen una escena de teatro como directores, en un contexto de formación institucional en el que el 'acto de enseñar' está, sobre todo, orientado por 'el acto de aprender' a ser directores. En el sistema 2, el estudiante-director debe desarrollar sus funciones de director a través de un complejo proceso de regulación del trabajo de los actores, diferenciado de las motivaciones que movilizan a los 'actores' a participar en él. En este sentido, la re-contextualización implica diferenciaciones en la esfera de los aprendizajes. Quienes están llamados a formalizar el aprendizaje son los directores' a partir de los gestos de regulación que les permite llevar a buen fin su proyecto de práctica artística.

En la medida en que la investigación en didáctica de las disciplinas ha propuesto modelos para analizar el aprendizaje como resultado de una actividad conjunta profesor/alumnos, movilizamos los siguientes conceptos para describir el funcionamiento de nuestros dos sistemas.

\section{Mesogénesis}

la evolución del medio didáctico y de los contenidos de enseñanzaaprendizaje que emergen y se modifican en el medio didáctico. En nuestro caso, partimos del postulado que el dispositivo complejo de los énfasis produce un medio didáctico principal: el espacio énfasis de teatro dramático. que resulta de la interacción de los medios didácticos de varios sistemas de formación. En el marco de nuestra investigación, situada en el dispositivo de 9 no semestre, los dos sistemas básicos son los descritos como sistema 1 y sistema 2 en el esquema 1: el espacio de la práctica artística, medio con el cual el estudiante-director entra en interacción y "produce" los saberes que se abordarán de manera reflexiva en el sistema 1. El interés de movilizar el concepto de medio didáctico como categoría de análisis, es el de poder describir las interacciones entre estos varios contextos didácticos presentes en el dispositivo y dar cuenta, como lo esquematizamos en el cuadro No. 1, de los procesos de transposición didáctica de los saberes que surgen en este proceso (Chevallard, 1990). En efecto, el dispositivo de formación en el énfasis hace interactuar diferentes agentes en diferentes sistemas didácticos (Leutenegger, 2009).

\section{Topogénesis}

Esta categoría permite describir los procesos de acción conjunta y los cruces entre dos categorías de roles y funciones presentes en toda situación didáctica. Por una parte, las interacciones de los roles de docente y de estudiante en cuanto a las funciones que asumen para que se logre la construcción conjunta de la actividad didáctica. Son estas 
dos categorías de agentes sociales -docente y estudiantes- quienes producen (docente) y modifican (docente y estudiantes) el medio didáctico (procesos de mesogénesis). Desde el punto de vista topogenético, este primer tipo de relación docente-estudiante se cruza con la evolución de las relaciones entre experto-novato (Rickenmann, Lagier y Mili, 2009). En efecto, dado que la relación didáctica se crea a propósito de saberes y de actividades específicas al teatro como disciplina, las interacciones no se dan solamente entre los estatutos de docente y de estudiante, sino entre los estatutos de experto y de novato. En el caso del dispositivo estudiado, este segundo tipo de relaciones se desarrolla de manera específica a partir de los roles de director y de actores que deben asumir los participantes.

\section{Cronogénesis}

Finalmente, la organización temporal de las actividades y tareas que proponen los estudiantes/directores a los estudiantes/actores Isistema 2) nos da indicaciones sobre la manera como los estudiantes/directores ordenan, jerarquizan y articulan los diferentes tipos de conocimiento vinculados al objetivo principal de construcción del rol de director y de sus relaciones con la docencia (sistema 1). El análisis del espacio énfasis, pone de manifiesto la importancia de 'contar con el tiempo necesario' para la asimilación de saberes, la reflexión sobre las funciones y las necesidades propias de constructos similares pensados hacia espacios de formación. Esta organización produce una cierta "forma" del saber, una transposición particular que nos permite describir qué saberes fueron efectivamente enseñados/construidos por los diferentes agentes sociales en los diferentes espacios de este dispositivo complejo, y de qué manera los estudiantes-directores los transponen, integran, re-contextualizan y re-personalizan.

\section{El problema: interrogar la práctica artística como espacio de aprendizaje}

Al proponer la investigación al interior del espacio académico énfasis en teatro dramático, nos preocupaba esencialmente cómo los espacios de construcción del rol de director al interior del énfasis podían aportar a la construcción del rol docente del futuro formador. Por esto la pregunta que guió nuestras pesquisas es ¿Cómo aporta el énfasis de teatro dramático en la construcción del rol docente a través de las relaciones y tensiones entre los roles de estudiante (sistema 1) y de director (sistema 2)?

El espacio central de la construcción del rol de director se da a partir de la acción de dirigir. En nuestro dispositivo se formalizan unas prácticas artísticas en el que hacen 'la experiencia' de ser directores, en el que son centro de su propia formación, a la vez que desarrollan con 'los otros' los gestos y las funciones que les permiten reflexionar sobre el camino a tomar, la pertinencia de sus decisiones, el modelo particular que en este contexto re-personalizan.

\section{Metodología}

En este texto analizaremos el proceso hacia y de prácticas artísticas ${ }^{45}$ de noveno semestre de los estudiantes que hacen parte del sistema énfasis de teatro dramático.

45 Este nombre obedece a que justamente en este semestre los estudiantes también llevan a cabo las
Para el análisis de los datos que emergen de las narraciones y textos de los estudiantes, hemos movilizado básicamente el concepto de medio didáctico (Brousseau, 1991), que nos permite describir los elementos de saber en juego a partir de la manera como se sitúan en los medios materiales y simbólicos de los sistemas didácticos 1 y 2 . La interpretación de las situaciones de enseñanza-aprendizaje se hace a partir de una lectura dinámica de la actividad resultante entre estos dos sistemas.

La investigación didáctica ha puesto en evidencia que los docentes (de cualquier disciplina) al interior del aula cumplen cuatro funciones importantes en sus dispositivos cotidianos: definición ${ }^{46}$, devolución ${ }^{47}$, regulación ${ }^{48}$ e institucionalización ${ }^{49}$. Los conceptos hacen parte del "modelo de la acción docente" propuesto por Sensevy, Mercier y SchubauerLeoni, (2000) y Sensevy y Mercier (2007) en el marco de la Teoría

prácticas pedagógicas en aulas escolares y definen los inicios de lo que será su perfil como docentes.

46 En el acto de definir, el docente explica el medio didáctico, los objetos de conocimiento, les "reglas del juego", en fin, los diferentes parámetros de la situación educativa que propone a sus alumnos (R. Rickenmann.

Op.cit.)

47 El acto de devolución implica aceptar la verdadera participación del "otro", del alumno, con sus conocimientos, con sus habilidades, en fin, con sus maneras de interpretar las expectativas del profesor.

48 Devolución-regulación son las dos nociones que nos muestran más claramente la mediación docente en la relación didáctica: ni acto de poder, ni “laisser-aller”, la relación didáctica se construye a partir de un sistema de expectativas mutuas, estructurado por las relaciones profesoralumno sobre las que reposa el contrato didáctico fijado por la institución escolar, y que sin estos el propio hacer desde el teatro no se percibe posible.

49 Institucionalización, que consiste en aquellos gestos profesionales con los que el docente valoriza, con respecto a los contenidos de enseñanza, los procesos y resultados de los alumnos que corresponden a éstos, también supone un campo de definiciones en esta actividad conjunta específica. 
de la Acción Didáctica Conjunta (TADC). Esta investigación propone dilucidar cómo estos gestos profesionales del docente nos sirven para caracterizar las intervenciones del estudiante/director en el sistema 2 en función de lo que se problematiza en el sistema 1. Este objetivo es particularmente relevante en el dispositivo de prácticas artísticas en la medida que los procesos mismos del montaje implican el desarrollo de competencias para favorecer la dimensión participativa y cooperativa (sistema 2).

La naturaleza misma de esas 'actividades' y 'juegos teatrales' supone gestos de devolución y de regulación de la actividad entre el director y el actor.

Así mismo, el concepto de definición es pertinente en la medida en que la propuesta de la actividad a los estudiantes/actores involucra una dimensión que es propia de la acción docente, y es asimilado por los estudiantes/actores a través de los procesos de acomodación de 'aquello' que comporta el teatro.

Por último, está el acto de institucionalización. Los estudiantes participantes de las actividades hacia el desarrollo de objetivos viables, de ser propuestos por un formador en artes escénicas, presuponen una evaluación permanente de los 'descubrimientos' que hacen en sus intervenciones (Toporkov, 1961). En los entrenamientos el diálogo entre los 'actores' es permanente para fijar partituras y gestos que enriquecen el quehacer artístico (Grotowsky, 1998). Por ello, buscamos identificar y describir la importancia de la memoria didáctica como una acción que fija partituras de acción a la vez que propone puntos específicos de reflexión sobre los avances en el trabajo de aula, sobre los saberes a través de los cuales los estudiantes/directores socializan y comparten el resultado de la actividad conjunta del montaje.

\section{Instrumentos de análisis}

Como parte del dispositivo de investigación se tuvieron en cuenta, dentro de los tres semestres que duró esta investigación, los siguientes instrumentos:

a. Bitácoras (Vanhulle y Schilling, en imprenta).

b. Videoscopías.

El análisis de las sinopsis y de las transcripciones del material de video se estructuran así, vistos a partir de los conceptos de meso, topo y cronogénesis ${ }^{50}$, categorías de la TADC. Para efectos de una ilustración de nuestro análisis, en los fragmentos de ejemplificación indicaremos gráficamente los indicios relativos a fenómenos mesogenéticos; los indicios. topogenéticos y los indicios relativos a fenómenos cronogenéticos.

Indagaremos los datos de esta investigación a partir de las evidencias identificadas en las interacciones verbales, gestuales y proxémicas, así como del material escrito que producen los diferentes agentes del dispositivo (formadores universitarios, estudiantes/directores, estudiantes/actores).

Este modelo nos permite una caracterización de los diversos elementos y agentes de las situaciones observadas y, más que nada, de las relaciones que se tejen entre ellos. Es así como podemos entender 
los procesos de transposición de los objetos y prácticas teatrales al interior del aula universitaria.

El análisis. Un aprendizaje fundamental desde el ejercicio de dirección teatral: la creación de un lugar para 'el otro' en la relación educativa

El ejercicio de la práctica artística se inicia formalmente en el momento en que los estudiantes presentan y socializan ante sus pares el proyecto de montaje. En este esbozan sus intenciones de dirección señalando el modelo a seguir y las justificaciones de su elección. Estas intenciones se legitimarán en las socializaciones que hacen de la propuesta ante los estudiantes de los semestres inferiores para convocarlos como actores de esta práctica.

\section{Estudiante 1 E.1}

El ejercicio de dirección es el que más me motiva, pues no depende sólo de mis ideas, sino que pone en juego la creación con el otro. Cada tarde en la que debía desarrollar este rol me sentía ante un ejercicio de gran responsabilidad, pues debía fundamentarlo teóricamente, lo relacionaba con la labor que ejerce un docente en el desarrollo de una clase, (...) y a ser flexible en el desarrollo de la misma, ser uno más en la clase que toma el papel de guía, cada sesión no estaba estrictamente planeada. Por el contrario, se transformaba en el desarrollo de la misma y de esta forma se daba inicio a la creación colectiva. En esta primera fase de desarrollo de este .trabajo se encuentra la importancia de la planeación y la fundamentación teórica, al igual que la fijación de aquel material que va surgiendo a través del desarrollo del mismo, en mi caso las improvisaciones. Por otra parte también se empieza a enfrentarlos problemas que surgen en escena, el camino que como director se debe tomar para conformar junto al actor un equipo de creación, que arroje un material de tal calidad que denote la satisfacción de las dos partes que hacen aportes al trabajo.

E.1 expone su interés de dirigir desde el plano de la motivación profesional (línea 1) en cuanto debe integrar el papel que juega 'el/los otro/s' en el trabajo (línea 2). En seguida hace referencia a la experiencia ya vivida en ejercicios de dirección con los pares, en los que justifica la responsabilidad frente al ejercicio en la necesidad de acudir a referentes teóricos comunes, conciencia de saberes emblema ajustados a los ejercicios, y hace la aclaración de la clase de relación que establecía sobre la responsabilidad con el contenido, al vincularlo con el papel que juega un docente en el desarrollo de una clase (líneas 4-5). Se evidencia así un avance en la cronogénesis por cuanto comienzan a emerger elementos constitutivos de lo que será su futuro perfil profesional como docente. Califica así al docente como aquel que debe tener conocimiento sobre los contenidos que circula, pero igualmente aquel que es capaz de introducir flexibilidad en función del "otro" de la relación (líneas 6, 7 y 8), como presupuesto de comprensión de las relaciones que se instalan dentro del aula. En el caso de E.1, esta flexibilidad se construye sobre la vinculación del modelo de creación colectiva que propone desde Brecht y el modelo de acción conjunta en el aula. Modelo que justamente depende de 'aquellos' hallazgos que desde las improvisaciones escénicas vayan resultando. E.1 se dispone a ver y escuchar lo que surja en los entrenamientos de montaje. La improvisación (línea 13) como metodología de creación dirigida, permite a los 'actores' poner en el escenario elementos escénicos básicos que se van afinando en función del plan general de 'la directora'. Estos elementos, correspondientes a la partitura escénica se refieren al ejercicio escénico en tanto 
texto, movimientos, gestos (Toporkov, 1961; Grotowsky, 1998) y la comprensión de 'esas circunstancias dadas' alrededor de los conflictos (Sanchis Sinisterra, 2002). La dirección escénica a partir de improvisaciones hace necesaria la participación activa de las dos partes. Del director que mira y escucha dando directrices, de los actores que proponen a partir de sus interpretaciones en una situación de creación situada, un ejercicio escénico (Stanislavsky, 1992; Brecht, 2004; Brook, 1973). E.1 es consciente de la importancia que tiene para la credibilidad y legitimidad de su acción de dirección integrar dentro del ejercicio de montaje los aportes de los 'actores'. Y es en el proceso de tomar decisiones sobre aquello que es pertinente o no al medio, de aquello que se acerca a la propuesta de la escena (línea 13) que el director identificará los problemas propios de la escena y las maneras de resolverlos, en este caso en forma conjunta con 'los otros' que participan del juego de montaje; con el objetivo general de construir un buen material (un medio que se transformal que comprometa la satisfacción de las partes en el ejercicio que, de otra manera, no sería una creación colectiva.

En el ejemplo anterior vimos como E.1 expone su propuesta de dirección desde la creación colectiva. Y de qué manera logra una interesante articulación entre las características de un tipo de práctica socioprofesional (la dirección como práctica colectiva) y su proyección futura en el ámbito de la docencia.

Una segunda estudiante hará su propia propuesta definiendo su ejercicio desde los conocimientos que ha construido alrededor del trabajo y propuestas de P. Brook. 


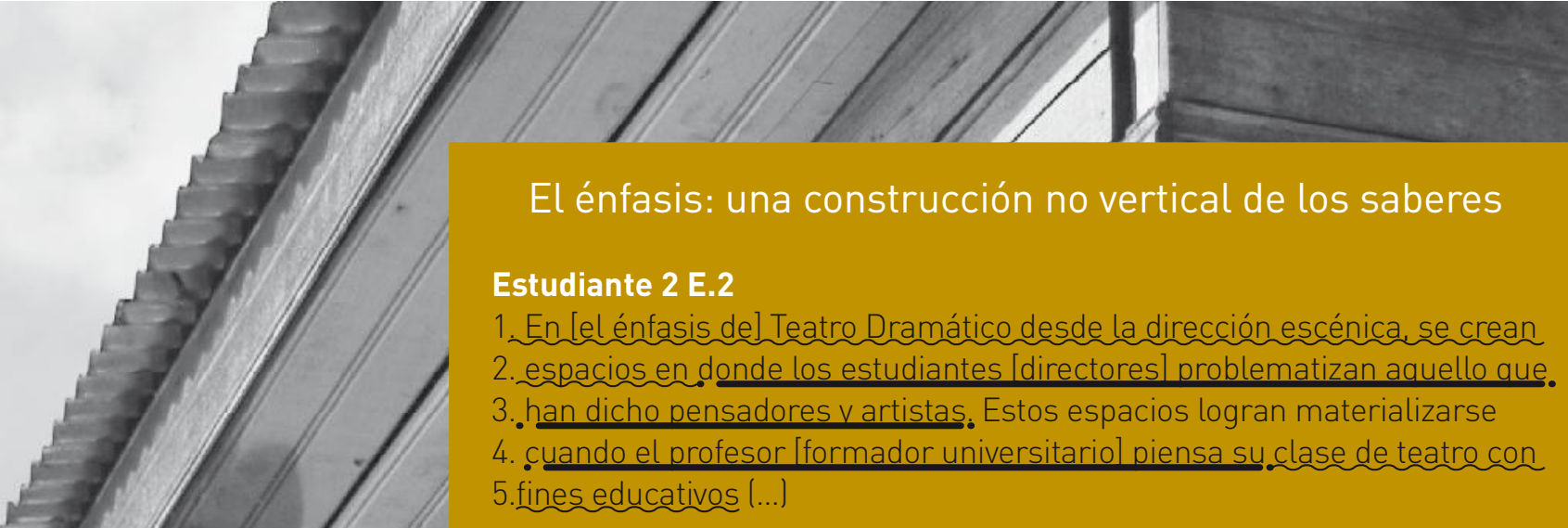

A su vez, E.2 puntualiza la importancia del espacio académico del énfasis (línea 1) no como un espacio de aportes teóricos que posteriormente serían llevados a la práctica artística, sino como un espacio de indagación para los estudiantes. En este sentido, E.2 comprende este espacio como el medio para la problematización de los referentes (línea 2) que aportan desde la teoría teatral y ayudan a la construcción de la práctica artística (sistema 2). Para que sea realidad el lugar de esta práctica, es necesario que dicho espacio haya sido proyectado topogenéticamente como un lugar para la construcción del estudiante (línea 4 y 5). Esta concepción que construye E.2 en este texto es contraria a la concepción vertical de la formación que venía considerándose para el dispositivo del énfasis, en la que unos formadores universitarios aportaban saberes teóricos a unos estudiantes, que posteriormente los movilizarían (aplicarían) en sus prácticas artísticas. En efecto, E.2 comprende el espacio del énfasis a partir de una importante devolución que hace la formadora universitaria en su programa, a partir de la identificación de aquellos elementos de la práctica artística que pueden tener interés en función de fines educativos.

\section{E.2}

6. La intuición ${ }^{51}$ es fuente de conocimiento porque surge de estructuras

7. mentales que el estudiante [director] hace cuando relaciona un conocimiento 8. con otro (...) La creatividad y la intuición como elementos de construcción.

9. aclaran el camino del estudiante de Teatro Dramático cuando éste se arriesqa a

10. proponer, o quizás cuando en el hacer desea, un deseo que se vuelve acción 11. [práctica artístical, v surge la creación de sentidos de 'hacer': (...) Tanto el 12. espacio de conocimiento teórico como el espacio de conocimiento práctico 13. deben estar al servicio del estudiante [director], quien puede con toda libertad. 14. presentar juicios de valor pero al mismo tiempo proponer maneras de abordar. 15. Los temas (...)

16. El docente [formador universitario] ciñe bajo una metodología al.

17. estudiante.pero también !e permite reconocerse v este reconocimiento es

18. valioso cuando es el estudiante quien toma las riendas de la clase con ideas.

19. Su propuesta escénica (...) guiero explorar la puesta en escena de la.

20. palabra, darle cabida al texto en escena para indagar sobre. lo que dice el 21. texto cuando se lee y qué hace el actor cuando lo representa. Desde la.

22. dirección centraré mis intereses en la interpretación del texto, la relación 23. actor-director....

51 Peter Brook. Provocaciones: la intuición. "Cuando comienzo a trabajar una pieza, empiezo con una profunda intuición, sin forma, que es como un aroma, un color, una sombra. Esa es la base de mi trabajo, de mi rol; así me preparo para los ensayos, cada vez que pongo una pieza". P.17.

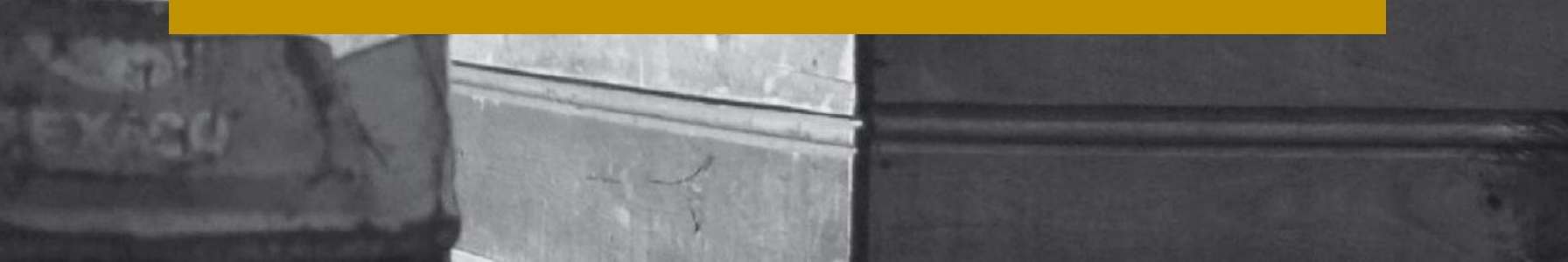


A renglón seguido expone los elementos que considera necesarios de explotar desde los discurso de P. Brook, de quien ella misma desprende su intención de creación escénica. Crear dimensiones de libertad desde el mismo espacio del énfasis, que le ha proporcionado ese lugar para indagar desde dónde construirse, y extenderlo hacia la relación con quienes realizará la práctica (líneas 12, 13, 14 y 15). En su discurso se evidencia la consciencia de las articulaciones entre los aportes de los diferentes espacios didácticos del dispositivo de formación: el espacio en el que ellos son estudiantes (cursos del énfasis), el espacio en el que ellos asumen una postura de dirección llas prácticas artísticas) y, también el espacio genérico de cualquier situación de formación con fines educativos (línea $3,17,18$ ) más puntualmente en la relación que describe en el párrafo final (líneas 16 a 23) respecto a la importancia de actualizar ese mismo espacio de libertad para las indagaciones cuando, como estudiante, asuma su rol director/docente quien asume el control del montaje o de la clase.

En los dos fragmentos constatamos cómo los estudiantes/directores toman conciencia de que su propio rol se define principalmente en función de tener en cuenta el lugar de los "otros de la relación" y en imaginar sus aportes.

Este aspecto es fundamental, por cuanto es uno de los vectores de transposición de los saberes en el dispositivo. En efecto, como lo analizamos a continuación, la estudiante tematiza saberes adquiridos por ella en el curso universitario del énfasis como instrumento para desarrollar su trabajo en las prácticas artísticas.

\section{La propuesta de dirección: un espacio de reflexión pedagógica}

Cada una de las estudiantes define en su texto la propuesta de dirección que pretende desarrollar. Y cada una articula en sus reflexiones el modelo de dirección que re-contextualizará en la práctica: Brecht y Brook respectivamente. Estas propuestas sintetizan, al interior de un abanico de opciones dadas durante los dos semestres anteriores, aquello que cada una considera desde su intuición la más apropiada para poner en marcha. La formadora ha propuesto un objetivo general para noveno semestre que relacione las funciones propias del director con los saberes, y ha dispuesto espacios diferenciados para desarrollar el programa. Por un lado, el espacio de discusión sobre lecturas y saberes emblema de la dirección (sistema 1), y por otro, el espacio de la práctica artística (sistema 2).

Si desde una concepción vertical de la formación se espera que el estudiante/director reproduzca en la práctica artística el sistema de relaciones que vivió en el aula del énfasis, en este dispositivo la imbricación de los dos sistemas no opera simétricamente.

Así, lo que será labor de definición del estudiante-director en las prácticas artísticas, surge del trabajo de devolución por parte de la formadora universitaria. Esta última considera como parte sustantiva del programa dar el espacio y el tiempo para que los estudiantesdirectores asuman las responsabilidades en la asunción de su rol de director en la práctica artística. Esta devolución es aceptada por los estudiantes, quienes se preparan para 'hacerse cargo' de su espacio de desarrollo: preparan un proyecto, lo discuten, lo socializan y lo presentan como la 'propia definición' de lo que será su práctica artística. En este sentido podríamos decir que la labor de definición de la formadora universitaria es "de largo espectro": antes que imponer directamente un cierto tipo de trabajo con los referentes teóricos de la dirección escénica, procura esencialmente definir las fronteras y características de una actividad consistente en un lento trabajo de construcción del rol de director. Y es a la vez una devolución de largo alcance: tomará los siguientes meses hacerse cargo del desarrollo de la tarea, en una alternancia compleja que implica aceptar los aportes y cuestionamientos que irán emergiendo desde las prácticas artísticas de sus estudiantes.

Notamos que las propuestas de dirección hechas por los estudiantes retoman contenidos específicos que le "hacen eco" a la devolución de la formadora universitaria: creación colectiva (Brecht, 2004), espacios de libertad, intuición, creatividad (Brook, 1992). Esta apertura hacia la dimensión conjunta y cooperativa de la actividad teatral no se limita únicamente a utilizar por imitación a aquellos dramaturgos y directores que basaron su trabajo en este tipo de principios. La frecuencia de los indicios topogenéticos en los fragmentos analizados, muestra disposiciones para el compromiso con 'los actores' en tanto que son "el otro de la relación" (dramática y/o pedagógica): vemos así en las reflexiones de E.1 y E.2 que sus proyectos incluyen espacios de escucha, de integración de aportes, de co-construcción del medio. Llama así la atención que en los dos casos aquí mostrados -E.1 y E.2- ponen de manifiesto la importancia de 'escuchar' y dar cabida a los aportes de quienes hacen parte del proyecto; es parte de la re-contextualización en su 
propia construcción como directores y como docentes.

Crear un ambiente de representación coherente con las dos propuestas de proyecto de práctica artística obliga a E.1 y a E.2 a discernir los términos específicos desde donde amplían los espacios de trabajo para las indagaciones, tanto de ellas como directoras, como de los 'actores' en la proposición de elementos para la escena. Las palabras y términos específicos relacionados con las acciones en las situaciones de representación son el inicio de la consolidación en la práctica de su propia intuición estética lprocesos de re-personalización), así como el principio de la motivación para quienes hagan parte con ellas de su proyecto de montaje Iprocesos de re-contextualización).

\section{La disposición del 'otro', un primer paso para la acción conjunta en la creación colectiva}

Cada estudiante de dirección presenta la obra, el autor y el tema que quiere trabajar desde la puesta en escena: E.1 El presidente, de Enrique Buenaventura, y E.2 Entre Nos, de Santiago Serrano. Vale la pena resaltar que aunque en la bitácora titulan el ejercicio de exposición como 'casting a los actores', a quienes realmente se audiciona con las propuestas es a los estudiantes/directores. Son ellos quienes se exponen para comprometer estudiantes en su rol de actores.

Los estudiantes de los primeros semestres explican la elección de director:

\section{Bitácoras 23 de abril}

Relatoría:

Casting a los actores.

1. Jef. quiere probar. conocer las propuestas que tienen desde dónde las están

2. tomando y para qué construirlas. Le qusta. el trabajo que quiere hacer E.1.

3. porque retoma a Brecht, le austa la idea de que la escena sea una construcción 4 . colectiva. En la UPN hay elementos que aún no les. dan v tener.

5. una experiencia.anterior desde la academia sería enriquecedor. Trabajó un

6. montaje de Moliere, le gusta Moliere.

7. A. quiere ver el contraste del trabajo que se hace en su grupo y el que se va a

8. desarrollar acá, además de encontrarle un sentido a su carrera enamorándose.

9. de ella en el trabajo.

La elección que hacen los estudiantes/actores se hace a partir del gusto, del interés (orientado desde lo socioprofesional del teatrol que despiertan las propuestas de los estudiantes-directores. El radio de expectativas ante las propuestas apunta a la conformación de grupos de trabajo que logren mantenerse hasta la finalización del proyecto. Señalamos en el fragmento las expresiones que tienen que ver con este gusto por su valor topogenético, porque consideramos que es un primer paso en la asunción del rol de actor y de las funciones implicadas en la participación en un montaje. Sobre todo porque, en la dinámica de presentación de proyectos de dirección, el deseo de participar en las prácticas artísticas es el principio del que se parte para la conformación de los grupos de montaje. Esta disposición (Stanislavsky, 1961) desde el deseo es muy importante en los entrenamientos teatrales. Esta disposición positiva hacia la escena es una de las premisas fundamentales para la acción escénica y hace parte de las concepciones más difundidas del trabajo de actor (por ejemplo, en Stanislavsky, 1961). Recordemos que en el escenario y en el trabajo de aula quien se expone a través de los ejercicios de construcción de personaje, de construcción escénica, es el mismo sujeto, su cuerpo, su personalidad, su intimidad. El modelo de trabajo colectivo tiene de esta manera buen recibo entre los 'estudiantes-actores'. Permite imaginar la importancia de los aportes personales en la construcción escénica, instala responsabilidades compartidas en el ambiente de representación y legitima el trabajo del grupo. El estudiante-actor A. hace parte de un grupo de teatro, y participar en la práctica le permite ampliar el espectro de las experiencias de grupo (línea 7). Le interesa contrastar lo que hace con su grupo. Por último señala que es a través de la práctica teatral donde es posible encontrarse con el teatro. Otra afirmación importante: el teatro es acción.

De esta manera podemos subrayar cómo, más allá de la relación formadora universitaria ßà estudiantes en el dispositivo académico del énfasis, las respuestas de algunos de los estudiantes invitados a participar como 'actores' contribuyen a dar sentido a las propuestas. Iden- 
tificamos aquí un ejemplo

de situación adidáctica

(Brousseau, 1991) en

la que una situación

"natural" (casting

de proyectos), que

no depende di-

rectamente de

los objetivos di-

dácticos del én-

fasis, termina

por participar de

la construcción

de sentido de lo

que está en jue-

go en la situación

didáctica de forma-

ción. En efecto, lo vivenciado durante el "casting de proyectos"

sirve como material de reflexión y de evaluación de los proyectos dentro del espa-

cio académico.

En este sentido, los enunciados del discurso de presentación de las propuestas serán las herramientas primeras para iniciar lo dialógico de lo que supone 'teatralmente' la creación colectiva, y educativamente, la acción conjunta. El interés por una u otra propuesta de dirección es el primer paso a esa disposición de producir un 'medio' y transformarlo en los avances del proyecto. El aula de la práctica artística, ese espacio de creación, representa las fronteras en los que se circunscribirán los poderes personales puestos en acción en el acto de dirigir (re-personalización).

Diríamos inclusive que el compromiso que asumen los estudiantes invitados legitima el saber que exponen los estudiantes de noveno semestre. Más adelante veremos cómo se llevan a cabo las prácticas artísticas y cómo las asumen unos y otros.

\section{La \\ práctica}

artística

\section{Acotaciones generales de dirección}

Los 'directores' deben hacerse cargo de la consecución de espacios para el trabajo de práctica. Deben también hacer un cronograma de 6 encuentros con una duración de tres horas como mínimo, durante dos meses. Es responsabilidad suya ajustar horarios para que los Đactores' no se ausenten de las otras clases de la formación. Cada 8 días durante las sesiones formales de clase énfasis, socializarán los aportes, las dificultades y los avances de la práctica. Deberán presentar bitácoras de trabajo, en las que consignen las necesidades propias de cada grupo, de cada trabajo y las reflexiones desde la dirección.

\section{Acotaciones necesarias a la sesión de ensayo}

El trabajo en cada sesión de la práctica artística se inicia con un entrenamiento. Este, a su vez, se inicia con un calentamiento que se va transformando en el ensayo mismo de montaje. El calentamiento permite alternar roles: quién dirige, quién cuestiona, quién sigue los lineamientos dados, y dentro de ello, cómo se van incorporando elementos propios del ejercicio escénico particular. Diríamos, inclusive, que es el espacio propicio para construir confianza mutua. De la disponibilidad de cada uno depende a su vez el éxito del mismo. El director, en este caso, observa: debe discernir la forma para no interrumpir abruptamente aquello que sucede, y redirigir las energías y la atención en función de su proyecto. No es solamente cuestión de moverse en el espacio, hacer estiramiento o instalar juegos escénicos, sino dis- 
El grupo ha estado trabajando una hora, en la cual los actores han hecho calentamiento, y luego de ponerse el vestuario necesario, han presentado el ejercicio que vienen ensayando ya en dos sesiones. El episodio da cuenta de los ensayos anteriores, las marcaciones hechas, incorporadas o no, las formas de interacción. (A.1 y A.2 son los actores. E.2 es la directora.)

1. E.2 detiene la escena. Hasta ahí. Dejemos 2. hasta ahí. ¿Qué. vieron? digamos... ¿qué 3 , faltó de eso que trabajamos la clase. 4. pasada? ¿Quéseles olvidó, qué? (silencio)

5. A.1 : Pues faltó,.... los tiempos

6. E.2 : Ajá, siguen faltando los tiempos

7. A.2: Mantener la voz.

8. E.2: Nooo, no fue tan marcado, está bien. 9. A A.2 sí le falta suavizarla un poquito

10. más... se pierde se pierde... por ejemplo 11. los objetos. Lo que trabajamos la clase 12. pasada con los objetos se perdió

13. completamente.

14. A.2: la velocidad al sacarlos.

15. E.2: exactamente. El ritmo al sacarlos.

16. Lo que significa el objeto como tal 17. para ti (hace gestos con la mano como si 18. los tomara) el ritmo al sacarlos al

19. sacarlos. Uish, lo habíamos trabajado la 20. clase pasada. El teido (gestos de rozar.

21. el teiido en el rostro. Despacio lento.

22. mientras repite suave el teiido, el 23.teiido) v marcamos unos. tiemnos. (baia 24. las manos lentamente aesticulando 25.con el. teiiido). Ush. Dejarlo ahí. Ne

26. demorarse tanto con él, y tampoce

27. sacarlo de una manera tan desordenada

28. porque șe ve feo, se ve fatal.(..) El

29. bolso... ser más preciso con los

30. objetos. Deiar el bolso, abrir el bolso

31. chun, sacar cada objeto, mostrarle el

32. objeto al público.(...) o sea que no se.

33. quede acá (sobre el pecho) porque no.

34. estamos viendo qué es. Describe con la 35. acción el obieto. (silencio). Pasémosla

36. otra vez. (E.2 se levanta para reiniciar).

37. E.1: ¿Qué pena! qué pena ( $A .1$ se

38. sorprende mira a A.1, escucha) (más

39. suave, se miraban,) no se están.

40. mirando están botando todo hacia acá y.

41. hacia el piso, jQué pena! comienza

42. cuando tú le dices qué pena, y no es qué 43. pena de disculpe,

¿sí? Con permiso, que 44. pena haberla molestado sino iqué

45. pena! de verdad lo siento, uy qué pena

46. y cuentas tres segundos, ahhhhh

47. tomando aire, que se agrande ese gesto: 48. Dios mío, con todo esto (exagerando),

49. ¿sí? que se vea el gesto primero, $x$

50. luego síla escuchamos.
En este fragmento vemos cómo funciona el ensayo del ejercicio escénico: la práctica artística. La discusión del ejercicio se centra en la manera como los 'actores' desempeñan su papel. Aparecen los temas puntuales que hacen parte de la caracterización de personajes alrededor de un conflicto escénico y la manera como se marcan las acciones. Aparecen las minucias de la preparación de los actores con respecto a la creación de los personajes y de éstos en el desarrollo veraz de la acción que la escena propone (Sanchis Sinisterra, 2002).

En la entrada, línea 1, alocución E.2 detiene la escena. Los actores han pasado la escena sin interrupciones. E.1 detiene la escena para valorar qué sucedió en la escena con respecto a gestos, marcaciones corporales, tono de voz trabajados la clase anterior (línea 1). Los actores saben que 'hasta ahí' significa detener la escena para volver a ella, para analizar. E.1 pregunta cómo ven la escena. Los actores han sentido esos equívocos y los nombran. A.1 responde sobre el manejo de los tiempos (línea 5), la voz (línea 7) y E.1 avanza en el análisis y nombra los objetos, sobre el trabajo realizado la sesión anterior, que no aparecen en el trabajo del día llíneas 10 a 12). A.2 acota con respecto a los objetos sobre el ritmo en su manejo (línea 14).

En el siguiente fragmento (líneas 16 a 36) E.2 aclara la relación entre el ritmo en las acciones y la manipulación de los objetos (línea 16 a 36) y 'actúa' el momento de sacar el tejido, señala con los gestos la acción mientras aclara el sentido de cómo lo hace. Importante la aclaración de cómo se ve la acción, hacia un público que mira (mirará) la escena (líneas 25 a 28 y 30 a 32) (Mukarovsky, 2000). Público que nombra directamente en la línea 32. Las acciones deben tener en cuenta al público, son para él.

E.2 propone retomar la escena, se levanta y súbitamente dice parte del libreto.

El tono de la actriz no corresponde al sentido de la frase, y E.2 la dice acotando la necesidad de comunicación visual entre los personajes (líneas 37 a 41).

La situación escénica final integra el tono de la voz, la mirada con el otro personaje, el gesto que lo acompaña: es lo que construye veracidad en la acción (líneas 41 a 50). 
cernir la pertinencia de ciertos ejercicios que adelanten la particularidad del ejercicio escénico. La responsabilidad del éxito de cada una de las fases de ensayo es distribuida. Cada rol tiene funciones específicas y se alimenta del trabajo de los otros.

Constatamos la complejidad en la alternancia de funciones que comprometen la eficacia en la gestión de los 'directores' y el desarrollo de tareas en el compromiso de los 'actores' para el logro del ejercicio escénico. Cada fase supone el desarrollo de clases diferentes de saberes, de compromiso particular que obliga a desarrollar en los estudiantes diversas facetas de gestión determinadas por las necesidades al interior del grupo y por los roles que dentro del ejercicio de la práctica se hacen necesarios.

Veamos en el siguiente ejemplo una secuencia específica de la construcción de personajes en una situación de ensayo.

Las acciones de E.2 dependen de las propuestas de A. 1 y A.2. Son los actores los que dan el ritmo de avance en la construcción del ejercicio. E.2 en este ejemplo interviene la escena en la medida en que los actores muestran cómo van integrando las marcaciones sobre los elementos que lo constituyen. El contrato didáctico que se instala en el espacio de la práctica artística obliga a los 'actores' a trabajar por fuera de la práctica, en tareas puntuales que van diseñando en la medida en que las necesidades del ejercicio así lo exigen. Los 'actores' se comprometen a cumplir esas acciones guía que el ejercicio exige, así como a incorporar los cambios que en cada sesión se fijan en la memoria didáctica para avanzar en la siguiente. Este punto marca un cambio fundamental con respecto a ese primer contrato que mencionamos anteriormente: el contrato entre formadora y estudiantes. Los 'actores' que trabajan con los estudiantes de la práctica artística no están motivados por calificaciones, notas o certificados de ninguna índole. Los estudiantes directores en cambio sí deben dar cuenta de una experticia lograda a través de los semestres para que esta práctica sea reconocida, y certificada la asimilación de unos contenidos, la construcción de una mirada, la circulación de una manera de gestionar su espacio. Debe, sobre todo, ser coherente en la acción de dirigir con 'aquello' que propuso en la formulación del proyecto, en este caso permitir a los actores decir de sí, de su trabajo (líneas 5, 7, 12). Las referencias al trabajo realizado en sesiones anteriores son gestos de regulación en el llamado al compromiso del trabajo extra-clase asumido por los 'actores'. En este sentido la aparición del público (ideal) es otro de los componentes de regulación propios del ser actor. Se actúa para un público, y el respeto hacia éste moviliza las exigencias del entrenamiento. Así también tenerlo en cuenta como una presencia que regula, a su vez, la calidad de los gestos. E.1 en su rol de directora puntualiza sobre la calidad de los gestos, la importancia del ritmo en las acciones, la veracidad en la correspondencia entre gestos, tono de voz, acciones inter-personajes. Estas acotaciones y la coherencia de ellas entre las sesiones de trabajo marcan otro elemento de continuación no solamente en el 'medio didáctico' del montaje, sino de los 'actores' en el trabajo. Vemos por tanto dos dimensiones en ese 'consolidarse' como grupo de trabajo: la coherencia en los ajustes de la dirección y la coherencia en las exigencias del compromiso.

En las reflexiones de E.2 para socializar con sus pares en el sistema 1 relacionado con la formulación de las funciones de su rol como directora de práctica artística, ésta escribe:

\section{Proyecto de práctica artística E.2}

1. Es importante que la directora en calidad de docente dé las herramientas a 2. sus actores para que estos se avuden a sí mismos, comprendan lo que. guieren.

3. decir o hacer analicen los errores cuando creen entender el personaie que. 4. van a caracterizar. Más allá de cualquier consideración el grupo que trabaja 5. en el montaje debe poder decir lo que piensa, lo que les austa. lo que no les. 6. qusta v lo que se podría hacer para superar las dificultades que se presentan? 7. en el transcurso de la puesta en escena.

Resaltamos la presencia en el ambiente de trabajo del sistema indirecto 3. Presenta en un trabajo escrito algunos elementos referentes a las funciones del director en su calidad de docente (línea 1) en tanto debe dar herramientas a los actores. Señalamos como indicio mesogenético las herramientas que aportan a los actores (línea 2) porque esas herramientas, contenidos, técnicas y reflexiones hacen parte de la construcción del medio. Son herramientas que aportan al rol del actor en su esfera de transformador. E.2 reflexiona en este trabajo sobre la importancia fundamental de que el director/docente priorice dinámicas de discusión al interior del grupo para que todos los participantes puedan opinar y decir de sí sobre las acotaciones en las dinámicas de hacer (líneas 4 a 6), para avanzar así en la construcción de personajes en función de la propuesta del director. Hace referencia al concepto de cultura de grupo (Barba, 1998) integrado como parte de las estrategias de gestión 
artística y académica para la consolidación del trabajo. Estas estrategias corresponden a los procesos de re-contextualización de los saberes devenidos de las prácticas socioprofesionales. El trabajo del grupo se consolida en el conocimiento articulado dentro del grupo, en los acuerdos implícitos de trabajo individual y colectivo ahora en el aula universitaria. El grupo se construye a partir de dinámicas de participación y conocimiento mutuo, de compromiso en un proyecto común (líneas 4 a 6).

\section{A manera de conclusiones: la acción escénica} conjunta, un modelo que se construye en el espacio escénico pedagógico

A través del análisis de los instrumentos fueron apareciendo una serie de pistas que nos obligan a reconsiderar el modelo 'imaginario' que creímos tener, para comprender el modelo que desde este proyecto se fue instalando. Desde el inicio del proyecto que corresponde al principio del espacio académico en séptimo semestre, la profesora desarrolló su clase desde una misma estrategia: espacios de discusión sobre cada uno de los textos de referencia, socialización de hallazgos, de ejercicios creativos tanto teóricos como prácticos. El objetivo "macro" de construir la mirada de los estudiantes en su rol de director definió las búsquedas individuales a partir de las socializaciones y construcción de preguntas alrededor del gusto y el interés individual en confrontación con los otros. Este objetivo, así como el dispositivo, corresponden a su vez a un modelo de ejercicio docente a partir de las competencias profesionales del rol de director, cuyo fin primero es en efecto dar los espacios para la confrontación individual sobre las intuiciones que se van elaborando en el transcurrir del tiempo hasta fijarse en la práctica artística. Desde el punto de vista de acción de la profesora universitaria, notamos que su función docente consiste en dar ciertos aportes teóricos bajo forma de lecturas (no es ella quien "da la teoría") y sobre todo, el otorgar el espacio y el tiempo para que los estudiantes construyan las reflexiones pertinentes que surgen de las articulaciones de los sistemas en los estudiantes. La misma socialización de los avances en los ejercicios permite identificar y reconocer los procesos de construcción de los conocimientos con los pares, y las muestras de los ejercicios redundan en los aportes de los 'otros' a la ampliación de perspectivas de la propia propuesta.

La metodología utilizada para esta investigación y su consecuente análisis permitió ver que nombrar el 'lugar del otro' en el discurso no basta. Por el contrario, es necesario agendar ese lugar en los diferentes protocolos que anteceden a los espacios de acción concretos: formulación de proyecto, invitación a estudiantes para hacer de 'actores', socialización con pares, estudio del 'papel' mismo del actor y del 'papel' mismo del director, concienciación paulatina del contexto específico del área de formación.

\section{Sobre mesogénesis}

En el análisis de las videoscopías y reflexiones escritas vimos cómo los procesos mesogenéticos corresponden a la dinámica de las discusiones y las puestas en escena, de la acción misma del montaje. Vimos cómo los estudiantes de noveno semestre inician la instalación de su perfil de directores desde una reconfiguración de sus intenciones de crear a partir de una idea, a través de la construcción de sus gestos de dirección en el espacio concreto de la práctica. En efecto, es la consciencia de la necesidad de "un lugar para el otro" desde la idea misma, la que está al origen de medios compartidos y conjuntos de los ejercicios de las prácticas, que les permiten a su vez construir sus roles y funciones de director. En este sentido vimos también cómo la participación activa y reflexiva de los 'actores' depende de que desde la formulación de los proyectos los estudiantes instalen espacios de construcción conjunta que se hacen concretos en los espacios de entrenamiento. El medio didáctico, en este caso, corresponde a varios sistemas que se alimentan y transforman recíprocamente. Veamos: como sistema 1, el aula se enriquece en las aportaciones permanentes de los estudiantes que a la vez alimentan sus propias reflexiones escuchando a sus pares. La dinámica misma de ampliar el espacio general del énfasis en dos sistemas diferentes, 1 y 2, transforma la clase general en un espacio de encuentro y crea 'ese espacio de libertad' en donde el estudiante, con el apoyo permanente de su formadora y sus pares, puede 'construir' su rol de director y algunas esferas de su 'rol de docente'.

Como sistema 2, el espacio de la práctica artística supone en sí mismo el proceso de montaje como medio didáctico para el estudiante-director. Este medio, el montaje mismo, se transforma en tanto los actores y el 'director' trabajan en ello, a la vez que cada una de las partes amplía su rango de experiencias desde su propio rol, funciones y competencias.

Sobre topogénesis: una disposición particular

Despierta interés la capacidad de asunción de diferentes roles 
de los estudiantes en cada una de las partes de este dispositivo. En el sistema didáctico 1 dirigido por la formadora, los estudiantes asumen su rol de estudiantes de licenciatura aportando en la construcción de saberes a partir de contenidos específicos y construyendo su propio conocimiento, integrando y re-personalizando los saberes en el contexto específico y concreto de la práctica artística (sistema 2).

En las prácticas artísticas los estudiantes asumen el rol de director construyendo sus objetivos en conjunción con los 'actores'. Cada estudiante asume una posición propia como director, pero todos asumen gestos docentes en las maneras de comprometer y sostener el compromiso con los estudiantes-actores. Aunque son autónomos en la dirección del espacio de la práctica artística (sistema 2), reasumen su rol de estudiantes socializando y discutiendo los problemas que se presentan en sus propios espacios de práctica, enriqueciendo el dispositivo, a los pares y a sí mismos.

Por su parte, vimos cómo los estudiantes-actores asumen el rol de actores desde el interés que despierta en cada uno las propuestas de los 'directores'. Este interés es el móvil fundamental que los dispone hacia la acción escénica. Esta disposición pone en juego las propias convicciones, las experiencias previas, los deseos de 'prestarse' para los ejercicios con los 'otros'. Y en este plano los dispone también para atender sugerencias, cristalizar a su vez, a través de ellos, los proyectos de quienes los dirigen. Tarea compleja que pone en el escenario pedagógico disposiciones y actitudes de compromiso permanentes. La diversidad de roles posibles -director, actor, público, dramaturgo, luminotécnico, docente, estudiante- permite que cada uno de los estudiantes se desplace desde su propio interés y puntualice sobre los saberes específicos que en la acción de unos y otros ponen en evidencia niveles de comprensión y apropiación de las nociones que, desde los contenidos establecidos en el proyecto curricular del espacio énfasis, se han programado. Según el medio didáctico que se instala en cada fase del dispositivo, los estudiantes desarrollan diferentes niveles de experticia en diferentes tipos de saberes.

\section{Cronogénesis, o el tiempo de la experiencia}

En este documento no profundizamos en esta categoría en los análisis puntuales. Sin embargo, queremos retomarla para hacer algunas generalizaciones sobre la relación tiempo/aprendizaje/creación/apropiación que se refleja en el dispositivo. La duración del espacio énfasis en la carrera tiene una extensión de tres semestres. Durante este tiempo, los estudiantes construyen el rol de director que se cristaliza en el proyecto de práctica artística en los diferentes espacios. Los ejercicios de asimilación de saberes puntuales y contenidos específicos se realizan con el tiempo, en primera instancia desde clases expositivas (sistema 1, que se inicia realmente dos semestres atrás) luego de lecturas, diferentes niveles de complejidad en ejercicios escénicos, y más adelante desde la discusión conjunta sobre estos últimos. Se desagregan de las exposiciones la toma de decisiones sobre aquellos contenidos y las maneras que cada estudiante elegirá como referente para su acción de dirección. Construir el propio dispositivo de dirección supone a su vez tiempos regulares extendidos a lo largo del semestre, que permitan simultáneamente a los 'actores' asimilar las propuestas y participar en ellas mientras construyen en sí mismo el texto dramático del montaje. En segunda instancia el dispositivo general, y según cómo lo disponga cada uno de los 'directores', compromete tiempos específicos fuera y dentro del aula de cada uno de los participantes para que, en el tiempo mismo de los ejercicios escénicos de construcción escénica, se materialicen las ideas iniciales.

Las referencias a cronogramas específicos para el desarrollo de cada una de las dimensiones del área, así como a trabajos puntuales planeados en el tiempo lla clase anterior, en dos semanas, ayer, el semestre anterior o el proyecto en el siguiente semestre, tres horas a la semana, dos horas a la semana, etc.) dejan entrever que la incidencia del tiempo en los procesos de apropiación y toma de decisiones en esta área merecería un análisis más profundo. La conjunción de saberes supone aquí experticias en entrenamientos corporales, vocales, conocimiento de tipos de personas particulares para situaciones específicas. Los procesos de lectura y escritura, no sólo de textos escritos, obligan asimismo a disposiciones de tiempo particulares.

\section{Acción-conjunta: pistas hacia un contrato didáctico coherente}

En el curso de los análisis surgen varias consideraciones:

La primera tiene que ver con la disposición permanente de los estudiantes a la reflexión continua y conjunta. Habíamos dejado de lado el hecho de que, desde el inicio de este curso de énfasis, los habíamos convocado a hacer parte de la investigación. Ellos construyeron con las investigadoras el proyecto y los instrumentos de análisis. Es decir que desde el inicio mismo del espacio académico formó parte del contrato 
didáctico entre la formadora y los estudiantes ser parte del proyecto de investigación. La segunda consideración, que se desprende de la primera, nos lleva a poner en evidencia que, como consecuencia de esta, asumieron con mucha seriedad la construcción de su proyecto, el estudio de los referentes propios del director y de los enunciados que plantearon que el espacio énfasis de teatro dramático es una materia, más entre otras, en la carrera de formación de formadores. Por tanto, la asunción y planificación del espectro de expectativas hacia los 'actores' suponía claridades en ese otro contrato didáctico que se fue instalando en el sistema de la práctica artística. La tercera consideración aparece desde esas expectativas que los mismos estudiantes reflejaron en sus diversos proyectos, escritos y documentos: 'el otro' en el marco macro de este proyecto de investigación corresponde a 'ellos', que fueron tenidos en cuenta como participantes capaces de acompañar un proceso de investigación, y que aunque fueron tenidos en cuenta en cada una de las fases de la misma y su participación se tuvo en cuenta desde la formulación del proyecto, se hicieron presentes en cada uno de los documentos e interpelaciones de ese lugar del 'otro'. Contradictorio que en el momento de escribir estas últimas reflexiones sobre el análisis hecho en este documento, traemos a la memoria esta realidad. Pero es necesario incorporarla. Nos permite constatar la importancia 'del otro' en los dispositivos de aula.

A nuestros estudiantes: Laura Santos, Jenifer Camacho, Ingrid Benítez, Farid Rincón, Niriyed Ojeda y Jesús Riveros, un agradecimiento enorme por habernos permitido investigar juntos.

\section{Bibliografía}

Abirached, R. (2000). La crisis del personaje en el teatro moderno.

Barba, E. (1998). El arte secreto del actor. México: Escenología. (1997). Teatro:

soledad, oficio y rebeldía. Buenos Aires: Ed. Catálogos.

Brecht, B. (2004). Escritos teatrales I, II y III. Editorial Alba.

Brook, P. (1992). Provocaciones. Buenos Aires: Ed. Fausto. (1973). El espacio vacío (arte y técnica del teatro). Barcelona: Ediciones Península.

Brousseau, G. (1991). IREM, Université de Bordeaux, Francia. Versión castellana de Luis Puig.

Cantillo Blanco, E. (2000). Apuntes sobre la adaptación dramática. Instituto Distrital de Cultura y Turismo.

(1999). Principios de dirección escénica. México: Colección Escenología.

Grotowsky, J. (1998). Hacia un teatro pobre. Siglo XXI Editores.

Mukarovsky, J. (2000). Estética y semiótica del arte. Bogotá: Plaza y Janés Editores Colombia S.A.

Rickenmann, R. (2006). La question de la réception culturelle dans les enseignements artistiques. MEI.

Rickenmann, R., Lagier, C. Y Mili, I. (2009). La construction sociale de l'expérience esthétique. Analyse didactique de séquences d'enseignement autour du patrimoine musical et artistique. En: S. Ragano (coord.), Didactique: approche vygotskienne, Special Issue de la Revue Internationale des Sciences de l'Education, No. 21, pp.129-141.

Sensevy, G. Schubauer-Leoni, M. L. y Mercier, A. L. (2007). Agirensemble: L'action didactique conjointe du professeur et des élèves. Presses Universitaires de Rennes.

Stanislavsky, C. (1999). Un actor se prepara. México: Ed. Diana.

Sanchis Sinisterra, J. (2002). La escena sin límites. Serje técnica teatral, España: Ñague Editora.

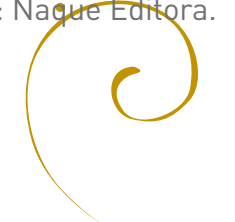

Schön, D. A. (1998). El profesional reflexivo. Barcelona: Paidós.

Toporkov (1961). Stanislavsky dirige. Argentina: Fabril editora.

CAROLINA MERCHÁN PRICE

CAROLAMERCHANAYAHOO.COM

PROFESORA DE PLANTA DE LA UNIVERSIDAD PEDAGÓGICA NACIONAL, PROGRAMA DE LICENCIATURA EN ARTES ESCÉNICAS. COORDINADORA DEL GRUPO EDUCACIÓN ARTÍSTICA, ADELANTA EN LA ACTUALIDAD DOCTORADO EN EDUCACIÓN EN LA UNIVERSIDAD DE GINEBRA, SUIZA.

NARDA ROSAS MARTÍNEZ

FORMADORA A CARGO DEL ESPACIO ACADÉMICO ÉNFASIS EN TEATRO DRAMÁTICO DE LA UNIVERSIDAD PEDAGÓGICA NACIONAL. LICENCIADA EN ARTES ESCÉNICAS DE LA MISMA UNIVERSIDAD CON MAESTRÍA EN ESCRITURAS CREATIVAS DE LA UNIVERSIDAD NACIONAL DE COLOMBIA. CO-INVESTIGADORA DEL GRUPO EDUCACIÓN ARTÍSTICA.

ARTÍCULO RECIBIDO EN MAYO DE 2011 Y ACEPTADO EN JUNIO DE 2011

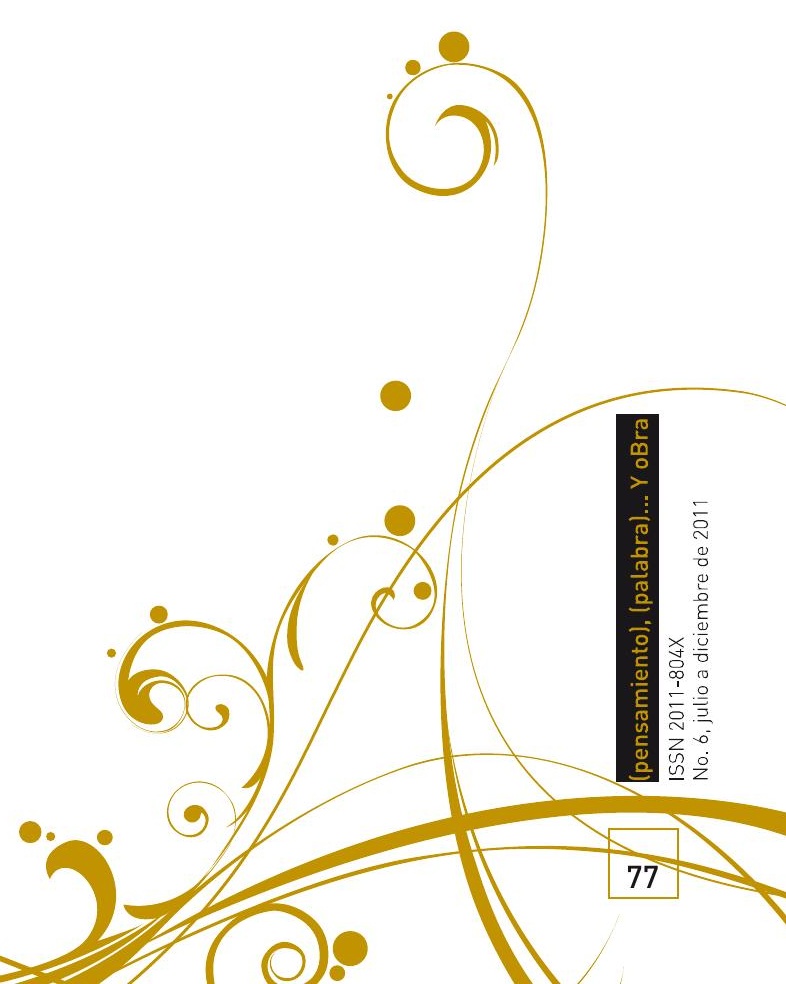

